\title{
A VIOLÊNCIA URBANA E A SENSAÇÃO DE INSEGURANÇA NOS ESPAÇOS PÚBLICOS DE LAZER DAS CIDADES CONTEMPORÂNEAS
}

\author{
D. M. M. C. LIMA* \\ Instituto Federal de Educação, Ciência e Tecnologia do Rio Grande do Norte \\ cdvc2@interjato.com.br
}

Artigo submetido em outubro/2015 e aceito em novembro/2015

DOI: 10.15628/geoconexoes.2015.3692

\section{RESUMO}

Este trabalho objetivou acrescentar algumas reflexões às já elaboradas durante a construção de uma tese de Doutorado na UFRN em 2006, acerca dos espaços públicos de lazer. As cidades passaram por grandes transformações no decorrer da história, sendo no espaço urbano onde o tempo se materializa a partir das ações desenvolvidas pelos seus habitantes, de acordo com as condições econômicas, ambientais e políticas existentes. No texto, evidenciamos os seguintes aspectos das cidades contemporâneas: a segregação socioespacial, as desigualdades na distribuição da infraestrutura urbana e a falta de democratização do uso do solo urbano, além de fatores visíveis e invisíveis que impregna no espaço público e influenciam os citadinos. Diante dessas considerações, constatamos que é necessário refletir sobre os diversos tipos de privação e as possibilidades de distribuição dos bens materiais e culturais para todos, por intermédio da solidariedade em detrimento de ações que incentivem a competição, que é geradora de conflitos.

PALAVRAS-CHAVE: Violência Urbana; Insegurança; Espaços Públicos.

\section{URBAN VIOLENCE AND INSECURITY IN THE FEEL OF PUBLIC LEISURE CITIES OF CONTEMPORARY}

\begin{abstract}
This study aimed to add some thoughts to the already produced during the construction of a doctoral dissertation in UFRN in 2006, about the public recreational areas. In the text, we highlight the following aspects of contemporary cities: the spatial segregation, inequalities in the distribution of urban infrastructure and lack of democratization of urban land use, and visible and invisible factors that pervades the public sphere and influence the townspeople. Given these considerations, we find that it is necessary to reflect on the various types
\end{abstract}

of deprivation and the possibilities of distribution of material goods and cultural rights for all, through solidarity rather than actions that encourage competition, which generates conflicts. Thus, access and recreational opportunities and take advantage of them, puts on the same level as other human rights. Accordingly leisure, as public policy, requires its connection with other sectorial policies towards the achievement of citizenship and a more just and egalitarian.

KEYWORDS: Urban Violence; Insecurity; Publics Spaces. 


\section{INTRODUÇÃO}

Neste texto, venho acrescentar algumas reflexões às já elaboradas durante a construção de uma tese de Doutorado na UFRN em 2006 (LIMA, 2006), acerca dos espaços públicos de lazer. Considero oportuno continuar tratando o tema, por este permanecer inquietando os pensadores que refletem acerca do espaço urbano na sociedade atual, e devido, também, a constatação de que as cidades continuam perdendo gradativamente os espaços públicos de lazer, e em decorrência disso, seus moradores vêm sofrendo queda na qualidade de vida.

As cidades passaram por grandes transformações no decorrer da história, sendo no espaço urbano onde o tempo se materializa a partir das ações desenvolvidas pelos seus habitantes, de acordo com as condições econômicas, ambientais e políticas existentes. Esse espaço se organiza por um processo social que reage a si mesmo e, ao mesmo tempo, é produto e reprodutor de materialidades e relações sociais existentes. De acordo com Lefebvre (2001): Não há obra sem uma sucessão regulamentada de atos e de ações, sem mensagens e sem códigos. Tampouco há obras sem coisas, sem uma matéria a ser moldada, sem uma realidade prática-sensível.

Cada local possui uma ambiência própria, baseada na articulação entre muitos fatores visíveis e invisíveis que se impregnam e definem sua identidade, influenciando o comportamento das pessoas. Esta ambiência é composta por aspectos físicos, culturais, sociais, muitos dos quais operam de modo inconsciente (THIBAUD, 2004).

Neste sentido, as pessoas ou grupos associam significados simbólicos e afetivos ao ambiente (emoções, cognições, crenças, comportamentos), se tornando ligadas a eles tanto cultural quanto emocionalmente. Enquanto o meio fornece importantes estímulos para a representação imagética dos sentimentos e emoções (TUAN, 1980).

No presente artigo, são acrescentados pontos importantes para o entendimento da percepção e utilização dos espaços públicos de lazer das cidades atuais, sendo aprofundadas a análise da violência e a insegurança que assola estes locais. Insere-se nesse estudo, ainda, a preocupação com o agravamento da sensação de risco e sua relação com os discursos acerca do aumento das ocorrências de atos violentos, fatores relevantes na análise da percepção generalizada de que os espaços públicos de lazer são perigosos.

São evidenciados, os seguintes aspectos das cidades contemporâneas: a segregação socioespacial, as desigualdades na distribuição da infraestrutura urbana e a falta de democratização do uso do solo urbano, além de fatores visíveis e invisíveis que impregna no espaço público e influenciam os citadinos.

Destaca-se, também, que o ser humano é coletivo ao mesmo tempo em que particular, na explicação destes fatores, o que permite a articulação entre os conhecimentos da Geografia e a Psicologia, pois ambas as ciências se ocupam em pesquisar o homem em sua relação com o meio. A Geografia, focando a perspectiva espaço-temporal em sua análise, enquanto a Psicologia, baseada na dinâmica da construção conceitual do sujeito através de sua subjetividade, no qual a materialidade espacial se constitui em conteúdos da consciência e percepções de mundo e nas formas de interagir com o meio. 
Segundo Elali (1997), grande parte do problema de estudarmos isoladamente cada fator envolvido na inter-relação entre o homem e as extensões que cria para si, parece relacionar-se à relativa estagnação do conhecimento dentro de cada setor, fruto da intensa compartimentalização da ciência em busca da superespecialização. Na mesma perspectiva, Peluso (2003), aponta que, devemos romper com a compartimentação entre os saberes e articular pensamento e práticas sobre a realidade do mundo em que vivemos e as pessoas que os habitam, pois são eles, com sua complexidade e dinamismo, os verdadeiros objetos científicos.

Milton Santos (1999) apresenta conceitos muito importantes que possibilitam trabalhar com processos psicológico-sociais/sociais/espaciais, designando a "Tecnosfera" como o meio técnico-científico-informacional que requalifica os espaços para atender aos interesses hegemônicos, e a "Psicosfera" como o reino das ideias, crenças, paixões e lugar da produção de sentido. , que sustenta a Tecnosfera. Estes são pares dialéticos, a "Tecnosfera", produz os insumos materiais para que a "Psicosfera", os transforme em conteúdos da mente e a sustente.

Aqui, desenvolve-se a possibilidade de inter-relacionar os saberes numa visão mais ampla, reconhecendo a limitação dos trabalhos anteriores e propondo refletir a interface entre o comportamento humano e o meio urbano, enfocando, a perspectiva oferecida pelos campos interdisciplinar da Psicologia e a Geografia.

\section{ESPAÇO PÚBLICO E A SENSAÇÃO DE PERIGO NAS CIDADES CONTEMPORÂNEAS}

Todas as cidades dispõem de lugares públicos e, por meio desses lugares de encontros e comunicações, se produzem uma espécie de resumo da diversidade socioespacial da população. $O$ espaço público apresenta um importante papel, pelo seu caráter relacional entre as pessoas, e concretiza-se fisicamente por ser local acessível a todos como: praças, ruas, praia etc. É então, qualquer tipo de espaço, onde não haja barreiras ao acesso e participação, onde as regras do convívio e o debate devam ser respeitados (LIMA, 2006).

Uma atividade no espaço público requer a co-presença de indivíduos, portanto, o espaço público é o lugar onde os problemas de uma coletividade se mostram. É o lugar de conflitos, de problematizações da vida social, como também é o lugar que permite o diálogo e o debate. 0 intercâmbio efetivo entre as pessoas no espaço público é a matriz que permite vislumbrar a densidade social local e resulta em possibilidades infinitas de acontecimentos. Para Lefebvre (2001b, p. 15): "a vida urbana pressupõe encontros, confrontos das diferenças, conhecimentos e reconhecimentos recíprocos (inclusive no confronto ideológico e político) dos modos de viver, dos 'padrões' que coexistem na cidade".

Sendo assim, é no espaço público onde, com maior clareza, apresentam-se as situações variadas: pessoais ou sociais, econômicas e culturais. É onde as carências de vários tipos se evidenciam, e a precariedade de condições de vida contrasta com as vontades de consumir os produtos criados pelas classes de maior poder aquisitivo. Então, nesses espaços as necessidades e vontades expressam-se em ações. E a problemática do conflito aflora mais nitidamente perante o cidadão. A diminuição do prestígio atualmente vem assim em consequência da sensação de perigo, o medo e a insegurança que se reflete.

O medo é um fenômeno psicológico, concebido como uma emoção devido à percepção de perigo presente e urgente que ameaça a preservação daquele indivíduo. Provoca, então, uma série 
de efeitos no organismo que o tornam apto a uma reação de defesa ou fuga, se a crença que o alimenta não for alterada, ele continuará habitando o inconsciente (DELPIERRE, 1974, apud SANTOS, 2003).

Assim, a análise do medo do cidadão que o afasta dos espaços públicos é de natureza complexa, estando diretamente relacionada a fatores concretos e abstratos que são agregados a esse espaço, e que influenciam o comportamento das pessoas que vivem no local ou o percorrem.

Estas considerações levam a articulação dos seguintes fatores, na análise da sensação de perigo que assola o cidadão no espaço público das cidades: à apropriação privada dos espaços comuns; à progressão das identidades territoriais; o emuralhamento da vida social em ilhas utópicas de isolamento social; e o crescimento da violência atrelada à sensação de perigo que caracterizam estes espaços.

\subsection{A apropriação privada dos espaços comuns}

A apropriação privada dos espaços comuns ocorre, principalmente, devido a um elemento da dinâmica das cidades, que é o crescimento do setor informal da economia: camelôs, guardadores de carros, bancas de jornal, trailler de lanches, barracas nas praias, que se desenvolvem quase sempre em lugares públicos de grande circulação, impedindo o livre acesso a todos. Ficam os lugares da vida pública restritos, muitas vezes, aos passantes ou consumidores de seus produtos.

A ocupação inadequada dos espaços públicos, também ocorre por moradores de determinadas áreas nobres da cidade e por empresários. Estes, ao adicionar áreas contíguas a suas propriedades, com vasos de plantas, outdoor, cartazes e tapumes, colunas de ferro e correntes, criando barreiras de acesso a determinadas ruas e ainda com a colocação de mesas e cadeiras ou balcões de mercadorias como prolongamento de restaurantes e lojas. Segundo Gomes (2002), a apropriação privada dos espaços públicos decorre da ausência ou ineficiência de normas que regulam o direito de cada um, para minimizar os interesses particulares que mobilizam o setor privado, principalmente, o setor da economia informal.

Sendo assim, a apropriação desses espaços é um dos fatores que torna o espaço público urbano um lugar de conflito entre usuários: os que têm o direito de circulação e os que se apropriam dos mesmos, limitando dessa forma a convivência pacífica e de respeito ao outro nestes locais.

\subsection{O acirramento de identidades territoriais}

As tendências ao conflito no espaço público vêm sendo moldadas, também, pela globalização e seu contraponto, que é o acirramento das identidades territoriais locais. Essas identidades apropriam-se do território a partir de um discurso fundamentado nas diferenças. Diversas identidades são territorializadas e se apropriam de praças, ruas e calçadas, muitas vezes com seus símbolos expostos nesses locais. Destacam-se as gangues de ruas, os usuários de drogas, os carteis de narcotraficantes, a vigilância armada, as torcidas de futebol, que dominam determinadas áreas públicas das cidades.

Todos esses movimentos apresentam algum nível de controle de determinadas localidades, restringindo o acesso apenas aos seus membros, e para tal, exercem geralmente a violência física 
ou simbólica aos que pretendem gozar dos seus direitos sobre os espaços públicos por eles apropriados.

Portanto, as diferenças e identidades sociais, quando exercidas com posturas antidemocráticas, refletem-se no território da cidade na forma de desavenças, negando a ideia de mistura e de respeito às diferenças, reforçando a ideia do estranhamento e do perigo do espaço urbano.

\subsection{O emuralhamento da vida social em ilhas utópicas de isolamento social}

Aumentam constantemente nas cidades as práticas defensivas, que isolam os citadinos, sob a alegação da necessidade de se proteger do perigo. O medo influencia assim a paisagem urbana, na medida em que surgem as cercas elétricas, os muros e as grades, fazendo com que cada vez mais os indivíduos, que não possuem esses itens em sua residência, sintam-se inseguros. Consequentemente, a familiaridade das pessoas com o espaço público vai se enfraquecendo, e este, vai se tornando cada vez mais estranho ao citadino.

O emuralhamento dos indivíduos e a construção das ilhas seguras - condomínios fechados, resorts, shoppings etc - contribuem para aprofundar o distanciamento entre pessoas e classes sociais, sendo o padrão monetário que determina a possibilidade de acesso a esses locais. Essas ilhas utópicas contêm áreas que são cópias dos espaços públicos das cidades (praças de alimentação, ruas com lojas, alamedas), porém estas cópias funcionam como a sua antítese, na medida em que recusam a diferença e inibem o acesso aos excluídos do mercado (mendigos, semteto).

Nesses locais, se exercem o controle arquitetônico, por meio da coação simbólica (câmeras, portas, símbolos proibitivos) e segurança privada (GOMES, 2002). Os espaços de sociabilidade se restringem à convivência com os semelhantes, pelo menos aqueles que mais se aproximam dos padrões de maior consumo e que se refugiam em espaços selecionados e controlados.

Perante esse quadro social e econômico, percebe-se que enquanto alguns moradores poderão comprar segurança, outros ficam a mercê do risco. Essa segurança, no entanto, só poderá ser realizada no nível das sensações, porque para sentir-se seguro é necessário estar confinado num espaço privatizado, pois, quem investe em segurança, se enclausura e se percebe isolado do perigo. Porém, nesses espaços, também tem aumentado os sequestros; roubos e atentados. Temse a "sensação" de proteção, enquanto a real possivelmente de violência, continua a existir.

O enclausuramento das pessoas deve-se, também, a outros elementos da vida social. Um dos fatores que contribui para esse isolamento refere-se às possibilidades de recebimento de grande número de informações sobre o mundo através da mídia, sem a necessidade de sair da residência. $O$ desenvolvimento dos meios de transportes é outro fator importante, ao permitir que as pessoas percorram grandes distâncias sem caminhar pelo espaço público, circulando apenas nos pontos de saída e chegada - restringindo-se para alguns segmentos sociais, o uso da via pública, apenas em pontos determinados.

Os espaços públicos abandonados pelos privilegiados ficam, então, entregues aos pobres, que deles necessitam no seu cotidiano, e não dispõem do poder reivindicatório das classes média e alta. Nesses espaços, não são priorizados investimentos públicos, ficando em consequência disto, geralmente desgastados, sem fiscalização das regras de uso e, aí predomina a violência e o 
desrespeito. Para os citadinos, a aparência descuidada e a falta de normatização dos usos, de grande parte dos locais públicos, aumentam o estranhamento e agravam a sensação de insegurança destes lugares.

Observa-se, também, que as políticas públicas que tratam da segurança estão geralmente voltadas para as consequências, de formas repressivas contra a população pobre e miserável. Esquece-se das mudanças no sentido da diminuição das contradições e distâncias sociais, e de ações que visem a mitigação dos problemas relativos à excessiva concentração urbana, partindo do planejamento socioambiental apropriado.

\subsection{A violência urbana $E$ a sensação de perigo nesses espaços.}

$\mathrm{O}$ argumento da violência urbana tem sido um dos principais motivos para a diminuição do uso do espaço público pelos mais favorecidos socialmente. A violência nos espaços públicos das cidades contemporâneas apresenta-se de várias formas, destacando-se: a descaracterização e destruição do patrimônio: os acidentes no trânsito: os roubos: os crimes: os assassinatos, as balas perdidas: o tráfico de drogas: a luta entre gangues, etc.

Nas últimas décadas, as variadas manifestações de violência física têm, com crescente intensidade, se colocadas na percepção social como um dos principais problemas da vida nas grandes cidades. Essa percepção envolve os processos mentais, a memória e outros aspectos que influenciam na interpretação dos dados percebidos e interferem no comportamento das pessoas, que são baseados na interpretação que se faz da realidade e não na realidade em si (GAZZANIGA e HEATHEARTON, 2005)

Muitas explicações têm sido apresentadas, tanto no plano da existência cotidiana dos indivíduos e grupos, quanto no da interpretação sociológica e psicológica. Na percepção social da classe dominante, a violência aparece geralmente como um problema funcional de controle social e administração da justiça. No entanto, as causas dessa violência e a percepção do risco ao cidadão que usa o espaço público, têm causas mais profundas, relativas à forma de vida e à organização social atual.

Existe uma relação direta entre a violência, a estrutura social e a organização social da vida cotidiana atual, na qual, prevalecem a individualização, a privatização dos interesses e o egoísmo. Segundo Yázigi (1997), é preciso alargar mais os horizontes, incorporando outras causas para a violência de hoje, entre outras a vontade do exercício do poder, que se encontra relacionada também com a relação de força no seio da sociedade.

Certamente, existe uma divergência quanto às explicações dada as causas e a intensidade da violência no interior do espaço urbano. É certo que a mídia, com seus noticiários com viés ideológico, agravam a percepção de insegurança, exacerbando os riscos que são acometidos aos citadinos no espaço público.

Constata-se que hoje em dia, a violência não é predominante apenas nos espaços públicos e exercida pelos menos favorecidos, pois vem se expandindo também, em áreas de estratos sociais mais privilegiados. Na mídia, os motivos alegados para a violência que ocorre em espaços privados são comportamentos patológicos, analisados como fatos isolados e individualizados. Enquanto nos noticiários em geral, a violência nos espaços públicos das cidades é mostrada como tendo tem uma íntima inter-relação entre criminalidade, pobreza e narcotráfico (RODRIGUES, 2002). 
Ao contextualizarmos o potencial da mídia em fazer circular repertórios interpretativos associados ao conceito de risco, observa SPINK, MEDEIROS E MELLO (2002) que, nas matérias em que o risco é usado como sinônimo de perigo, a palavra dá força ao argumento, ajudando a sinalizar a ameaça.

Compreende-se assim, que a sensação de insegurança e a percepção de encontrar-se permanentemente em risco ao fazer uso dos espaços públicos, podem incidir por meio da mídia no sujeito com maior intensidade que a insegurança de fato existente. Também, podemos considerar que a pauta da mídia, voltada para a violência, é consequência da ênfase dada a busca pela segurança na vida moderna, pois, o citadino de hoje "sente-se inseguro, ameaçado e amedrontado, mais inclinado ao pânico e mais interessado em qualquer coisa que tenha a ver com tranquilidade e segurança que os integrantes da maior parte das outras sociedades que conhecemos" (BAUMAN, 2009, p.13).

A Psicologia Ambiental e Social em diálogo com a Geografia Urbana e Populacional pode contribuir para este debate, ao propor a abordagem do risco a partir da perspectiva da interrelação do indivíduo com o espaço social e sua reprodução.

Como nos alertas Pinheiro (2003, p. 302), o fenômeno psicológico não pode ser compreendido como produção estranhamente "psíquica", distanciada das relações sociais e ambientais, a partir das quais nós elaboramos nossa existência". Para esse autor, toda Psicologia "é, de certo modo, forçosamente ambiental". Nesse contexto, o risco é considerado como qualquer possibilidade real ou simbólica, de que algum elemento ou circunstância existente num dado ambiente, possa causar dano à integridade do sujeito.

Assim, a contribuição da Psicologia permite maior compreensão ao "cidadão comum, perplexo e inseguro diante da realidade urbana atual, consequência de um desenvolvimento científico e tecnológico intenso e alucinante, que modifica substancialmente a paisagem dos assentamentos humanos" (PINHEIRO, 2003).

Nessa linha de raciocínio, o conhecimento desses riscos está diretamente associado às reações que envolvem a percepção dos indivíduos e as suas experiências e vinculações com seu espaço, além da percepção de risco articular-se à avaliação subjetiva do grau de ameaça potencial de um determinado acontecimento ou atividade.

Então, a sensação de estar correndo perigo, depende de uma multiplicidade de fatores, como o contexto e a inserção da pessoa em um determinado evento, a função ocupada em determinado espaço social, os aspectos culturais, a personalidade, a história de vida, as características pessoais e a pressão e/ou demandas do ambiente.

A sensação de insegurança como fenômeno das cidades atuais, pode ser consequência de uma construção histórica baseada na necessidade de proteção e de controle que, em algum ponto desse processo de transformação, deixa de priorizar a capacidade de solidariedade. Assim, os lugares públicos e as ruas vão se tornando de fato, cada vez mais perigosas. Essas áreas vão deixando de serem vistas como o lócus de sociabilidade, juntamente com as relações de vizinhança.

Nesse sentido, torna-se necessário pensar o espaço urbano como espaço de possibilidades, no qual os espaços públicos de lazer, que não esteja caracterizarem pelo ideário do privado, têm 
potencial para distanciar-se do pensamento capitalista, podendo assumir um papel privilegiado para a construção de uma solidariedade em prol de uma sociedade mais igualitária.

\section{AS POSSIBILIDADES DOS ESPAÇOS PÚBLICOS DE LAZER URBANOS}

Para Yázigi (2003), somente uma sociedade familiarizada com a democracia é capaz de respeitar o espaço público. A cidadania, nesse sentido, tem uma relação de pertencimento a um grupo e a um território, onde os indivíduos podem exercer os seus direitos e cumprir seus deveres em seus limites.

A questão do espaço público de lazer, não se restringe apenas à existência de condições ambientais favoráveis, como a existência de praias, rios, lagoas e reservas florestais, sendo necessária, nas cidades, a implantação de certos sistemas de circulação, infraestrutura, parques etc, que permitam os seus usos pelo citadino no tempo livre disponível (DÁLIA, 2006).

Entretanto, atualmente os espaços públicos de lazer urbanos não gozam de valorização e nem são entendidos como essenciais pelos gestores, não recebendo a atenção necessária por parte das políticas urbanas. Assim, o que acontece, geralmente, é o descaso e o conformismo dos diversos segmentos da população, no que diz respeito à reivindicação e ao cuidado acerca desses espaços.

Nas cidades, a desvalorização dos espaços públicos de lazer tem se constituído num fenômeno que ocorre paralelamente à privatização da esfera arquitetônica pública, na qual: os parques são abandonados ou cercados; as praias tornam-se segregadas e privadas, e, as ruas ficam desoladas e carregadas de perigos reais ou imaginários.

A verticalização, fenômeno crescente em muitas cidades médias e grandes, também vem se constituindo de uma forma que desvaloriza os espaços públicos, pois, ao concentrar moradias, não libera áreas livres para atividades coletivas, e muitas vezes, incorpora, indevidamente, como apêndice privado, outros espaços contíguos aos condomínios. A implantação das "áreas de lazer" nos edifícios está longe de corresponder à função de socializar perante a vizinhança, tornando-se áreas privadas, muitas vezes, de pouco convívio entre pares e raramente entre diferentes.

No entanto, a perda de prestígio dos espaços públicos e do isolamento humano não implica a impossibilidade histórica de mudança, pois existe dentro da sociedade contradições e conflitos que podem resultar em possibilidade de reação em prol de modificar o futuro a partir das práticas presentes, sendo possível a partir de uma práxis inovadora, um processo de redefinição nos quadros da vida social coletiva que, gradativamente, possa modificar as práticas sociais e espaciais a partir da contemporaneidade.

O desafio atual é, portanto, o de retomar o espaço público como lugar de uma participação ativa, normalizada e refunda-la como um espaço de política, de uma atividade cotidiana, de um agir relacional, sem deixar de sonhar com as utopias, porém com os pés na realidade, na prática diária consciente.

A violência existente nesses espaços deve ser pensada a partir de uma percepção mais ampla, que extrapole os interesses dos que não necessitam deles para as suas atividades do cotidiano. Deve-se refletir, principalmente, acerca dos principais motivos do perigo existente 
nessas áreas, e em que medida poderão ser superados os conflitos, a partir de novas formas de atuação nesses espaços.

Pois, a segurança de fato, pressupõe muito mais do que punição e enclausuramento. Pressupõe outra ética de valorização da liberdade, da alteridade, da solidariedade e da preservação coletiva da cidade, com a justa distribuição das riquezas e dos saberes.

Essa atuação cidadã deve basear-se numa nova forma de planejar esses espaços em prol de torná-los mais agradáveis e menos violentos. Para isso, essas áreas necessitam ser construídas com vistas às necessidades da comunidade usuárias do seu entorno, para guardar uma identidade com esta, e assim possibilitar um sentimento de pertencimento gerador de responsabilidades frente ao seu uso e sua conservação, além de uma normalização do uso desses espaços, sem descartar um policiamento preventivo do lugar.

Portanto, a ação democrática, em relação aos espaços de lazer, deve envolver uma mudança da mentalidade na utilização dos equipamentos, na busca de uma maior participação popular em atividades comunitárias, como também deve envolver a luta em defesa de um patrimônio ambiental-urbano e de uma melhor qualidade de vida. Pois os lugares se descaracterizam diante da sobreposição de produtos de lazer que estão na moda no mercado mundial e apresentam pouca identidade com o local. Atrelada às questões econômicas e conjunturais, a mídia exerce grande influência no comportamento das pessoas na cidade na atualidade, por meio da qual são criadas necessidades de consumo e impostos novos padrões de comportamento.

Para se possibilitar um lazer criativo e participativo para todos, é necessária uma justa distribuição do tempo e do espaço, somada a uma ação cultural democratizante, tendo por base a cultura popular que apresenta como ponto de referência o patrimônio cultural das artes, das ciências e da filosofia, articulada com uma postura crítica, para evitar o conformismo da imitação e reprodução simples do passado. (MARCELLINO, 2001).

A valorização do espaço público de lazer é uma questão pertinente ao poder público, pois a iniciativa privada e o investimento privado segregam cada vez mais a renda, onde os ricos têm todas as possibilidades que o capital pode proporcionar, e os pobres ficam apenas com alternativas de lazer restritas, e muitas vezes inadequadas. Cabe, assim, aos vários níveis de atuação do Estado, buscar soluções para criação, conservação e animação de espaços de lazer de acordo com as necessidades da população. Os governos locais não podem ficar reféns da política globalizante, que os coloca no insignificante papel de preparar a cidade para receber os novos padrões de produção do mundo global, como eventos esportivos ou elitizados, voltados principalmente para o turismo.

É necessário, assim, pensar o planejamento da acessibilidade ao maior número de pessoas aos espaços públicos de lazer disponíveis, o que requer o estudo do uso e ocupação dos espaços de moradia e seu entorno; de como a população ocupa seu tempo livre e quais suas preferências frente às possibilidades de lazer (RODRIGUES, 2002).

Os espaços podem ser pensados partindo dos próprios bairros, o que proporcionariam, aos moradores, uma vida pública no seu entorno, estimulando, assim, o convívio com os vizinhos. 0 citadino necessita de áreas próximas à sua moradia para que lá exerça atividades de lazer, evitando os deslocamentos, que já consomem parte do tempo e renda disponível, para essas atividades 
(SANTINI, 1993). Esses espaços das proximidades das residências devem ser planejados com equipamentos de lazer e mobiliário adequado, como: bancos, fontes de água e bebedouros, arborização, quadras poliesportivas, etc.

Esse tipo de planejamento exige, necessariamente, a interação de órgãos governamentais e a formação de uma equipe interdisciplinar com a participação da população interessada. Pois o que causa maior preocupação em relação ao planejamento dos espaços públicos urbanos de lazer, refere-se exatamente ao fato da simples existência física desses espaços, sem o devido uso, conservação e animação, negar a sua própria razão de existir. Nesse sentido, uma política urbana do lazer requer tanto o espaço físico, quanto a animação sociocultural desses espaços, o que envolve o planejamento de recursos destinados para construir, manter, animar e garantir sua ocupação democrática (MARCELLINO, 2001).

Dentro de cada cidade existe uma possibilidade local de mudança, consequência das características específicas das relações entre os diversos segmentos da vida urbana. A adoção de uma concepção societária de democratização considera, essencialmente, a ampliação da cidadania. É no lugar - e pela ação humana - que se concretizam as possibilidades de transformação e mudança na realidade social. Segundo Santos (1987), o cidadão é o indivíduo num lugar. A democracia somente será realizada quando considerar todos os cidadãos como iguais, independentemente do lugar onde estejam.

No debate acerca da democracia, existe uma necessidade de relacionar a cidadania às possibilidades de ação do cidadão, o que permite afirmar que a dimensão física do espaço público, tanto quanto a esfera política são indispensável à realização da democracia. "Todas as atividades humanas são condicionadas pelo fato de que os homens vivem juntos; mas a ação humana é a única que não pode sequer ser imaginada fora da sociedade dos homens - depende da constante e presença do outro" (ARENDT, 2004, p. 31).

Então, a democratização do lazer não pode estar dissociada da realidade urbana e da reflexão acerca da superação das contradições existentes na vida social como um todo. É necessário refletir sobre os diversos tipos de privação e as possibilidades de distribuição dos bens materiais e culturais por todos. Dessa forma, ter acesso e oportunidades de lazer coloca-se no mesmo patamar dos anseios e expectativas e direitos a serem conquistados pelo cidadão.

\section{CONSIDERAÇÕES RELEVANTES}

Partimos da compreensão que, nas cidades, o espaço público tem um importante papel, pelo seu caráter relacional entre as pessoas, e concretiza-se fisicamente por ser local acessível a todos como: praças, ruas, praia etc.

Considerando que o espaço se organiza por um processo social que reage a si mesmo, e que esse processo é ao mesmo tempo o produto e reprodutor de materialidades e relações sociais existentes. E que as pessoas ou grupos associam significados simbólicos e afetivos ao ambiente (emoções, cognições, crenças, comportamentos e ações), se tornando ligadas a eles tanto cultural quanto emocionalmente. Por outro lado, o meio fornece importantes estímulos para a representação imagética de nossos sentimentos e emoções.

Nesse sentido, é enfatizada a interface entre o comportamento humano e o meio urbano, enfocando a perspectiva oferecida pelos campos interdisciplinar da Psicologia e a Geografia, para 
a análise do risco e da sensação de perigo real e imaginário que predomina na percepção do cidadão, cujo medo provoca um estranhamento e afastamento dos espaços públicos destinados ao lazer.

Ressaltam-se também os vários fatores para o entendimento da violência nos espaços públicos de lazer atuais. E destaca-se que a sensação de insegurança e a percepção de encontrarse permanentemente em risco ao fazer uso dos espaços públicos pode incidir no sujeito com maior intensidade que a insegurança de fato existente. Nessa linha de raciocínio, o conhecimento desses riscos está diretamente associado às reações que envolvem a percepção dos indivíduos e as suas experiências e vinculações com seu espaço, e a percepção de risco refere-se à avaliação subjetiva do grau de ameaça potencial de um determinado acontecimento ou atividade.

Então, a sensação de estar correndo perigo, depende de uma multiplicidade de fatores, como o contexto e a inserção da pessoa em um determinado evento, a função ocupada em determinado espaço social, os aspectos culturais, a personalidade, a história de vida, as características pessoais e a pressão e/ou demandas do ambiente.

A sensação de insegurança como fenômeno das cidades atuais, pode ser consequência de uma construção histórica baseada na necessidade de proteção e de controle que, em algum ponto desse processo de transformação, deixa de priorizar a capacidade de solidariedade. Essas áreas vão deixando, assim, de serem vistas como o lócus de sociabilidade, juntamente com as relações de vizinhança.

Consideramos então, necessário, pensar o espaço urbano como espaço de possibilidades, no qual os espaços públicos de lazer têm potencial para distanciar-se da reprodução capitalista, podendo assumir um papel privilegiado para a construção solidária de uma sociedade mais igualitária.

O desafio a ser transposto é o de retomar o espaço público como lugar de uma participação política ativa, normalizada e refunda-la numa atividade cotidiana com vista nas utopias, porém com os pés na realidade, numa prática diária consciente.

A violência existente nesses espaços deve ser pensada a partir de uma percepção mais ampla, que extrapole os interesses dos que não necessitam deles para as suas atividades do cotidiano. Deve-se refletir principalmente acerca dos principais motivos do perigo existente nessas áreas, e em que medida poderá ser superada os conflitos a partir de novas formas de atuação nesses espaços. Pois, a sensação de segurança de fato, pressupõe refletir acerca dos conflitos inerentes das relações humanas numa outra ética de valorização da liberdade, da alteridade, da solidariedade e da preservação coletiva do planeta com a justa distribuição das riquezas e dos saberes.

Assim, a democratização qualitativa e quantitativa do lazer deve estar inserida na realidade total, requerendo a superação das contradições existentes na vida social como um todo. É necessário refletir sobre os diversos tipos de privação e as possibilidades de distribuição dos bens materiais e culturais para todos, por intermédio da solidariedade em detrimento de ações que incentivem a competição, que é geradora de conflitos. Dessa forma, ter acesso e oportunidades de lazer e delas usufruírem, coloca-se no mesmo patamar dos outros direitos humanas. Nesse sentido o lazer, como política pública, requer a sua conexão com as outras políticas setoriais em prol da conquista da cidadania e de uma sociedade mais justa e igualitária. 


\section{REFERÊNCIAS}

1. ARENDT, Hannah. A condição humana. Tradução de Roberto Raposo. 10. Ed. Rio de Janeiro: Forense, 2004.

2. BAUMAN, Zygmunt. Confiança e medo na cidade. Rio de Janeiro: Jorge Zahar, 2009.

3. ELALI, Gleice Azambuja. Psicologia e Arquitetura: em busca do locus interdisciplinar. Dossiê Psicologia Ambiental, Estudos de Psicologia Ambiental, 1997.

4. gazZANigA, M. S.; HeAtheARTON, T. F. Ciência Psicológica: Mente. Cérebro e comportamento. Porto Alegre: Artmed, 2005.

5. GOMES, Rita de Cássia, SILVA, GOMES, Rita de C.C. (Org.). Globalização e desigualdade. Natal: A.S., 2002.

6. LEFEBVRE, Henry. 0 direito à cidade. Tradução Rubens Eduardo Frias. 2. Ed. São Paulo: Centauro, 2001.

7. LIMA, Dália Maria Maia Cavalcanti de. $\mathbf{O}$ espaço de todos, cada um no seu lugar: 0 uso dos espaços públicos destinados ao lazer em Natal. Natal, RN, 2006.

8. PELUSO, Marília L. O potencial das representações sociais para a compreensão interdisciplinar da realidade: Geografia e Psicologia Ambiental. Estud. psicol. (Natal)vol.8 no.2 Natal May/Aug. 2003.

9. PINHEIRO, J. Q. (2003). Psicologia Ambiental brasileira no início do século XXI. Sustentável? In O. H. Yamamoto \& V. V. Gouveia (Orgs.), Construindo a psicologia brasileira. São Paulo: Casa do Psicólogo.

10. RODRIGUES, Adyr Balastreri. Lazer e espaço na cidade pós-industrial. In: Licere, Belo Horizonte, v.5, n.1, p. 149-164, 2002.

11. SANTINI, Rita de Cássia Giraldi. Dimensão do lazer e da recreação: questões espaciais, sociais e psicológicas. São Paulo: Angelotti, 1993.

12. SANTOS, Milton. A natureza do espaço: técnica e tempo, razão e emoção. 3 ed. São Paulo: Hucitec, 1999.

13. SANTOS, Luciana Oliveira dos. O medo contemporâneo: abordando suas diferentes dimensões. Psicol. Cienc. Prof. v.23, n.2 Brasília jun, 2003.

14. SPINK, Mary Jane P., MEDEIROS, Benedito e MELLO, Ricardo Pimentel. Perigo, Probabilidade e Oportunidade: A Linguagem dos Riscos na Mídia. Psicol. Reflex. Crit.Vol.15 no.1. Porto Alegre 2002.

15. THIBAUD, J.P. (2004). $\mathbf{O}$ ambiente sensorial das cidades: para uma abordagem de ambiências urbanas. In E.T. Tassara (Orgs.). Psicologia e ambiente. SP: EDUC.347-361.

16. TUAN, Yi-F. Topofilia: um estudo da percepção, atitudes e valores do meio ambiente. SP: DIFEL, 1980.

17. YÁZIGI, Eduardo. $O$ mundo das calçadas: por uma política de espaços públicos em São Paulo. Tese (Livre-Docência) - USP, Departamento de Geografia, São Paulo, 1997. 